ص ص ص[?

\title{
التحالفات الوظيفية
}

دراسة تطبيقية في الشركة العامة للمنتوجات النفطية_الشمالية

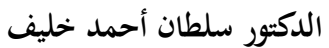 \\ أستاذ مساعد -المعهد التقني

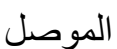 \\ alnofal 57 @yahoo.com
}

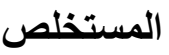

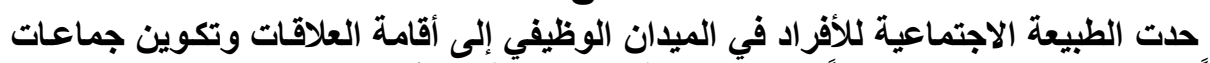

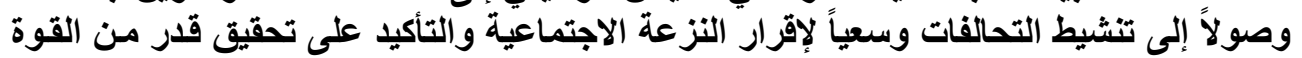

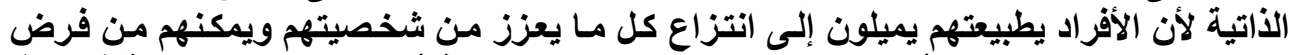

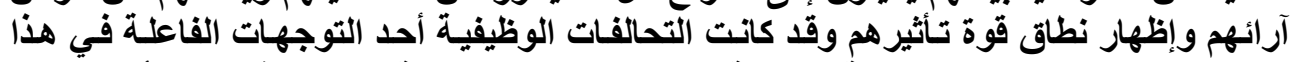

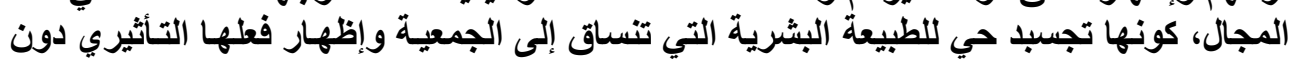

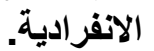
وقد سعت الاراسة إلى الإجابة عن التساؤلات الآتية:

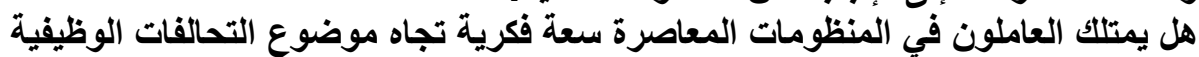

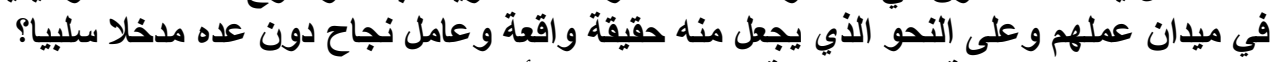

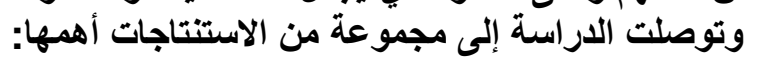

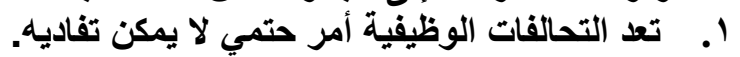

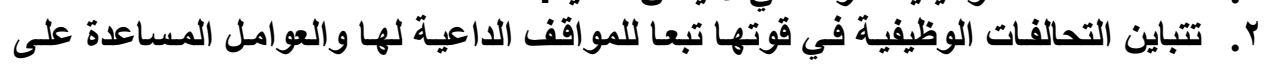
تكوينها. r. تمثل التحالفات احد استراتيجيات التأثيرية في ميدان العمل الوظيفي.

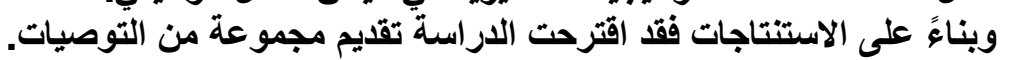
الكلمات المفتاحية: التحالفات الوظيفية، أنواتئية الواعها.
\end{abstract}

Job Coalitions: Application Study General Company for Oil Products/ Northern

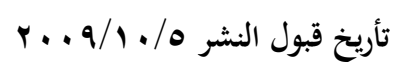

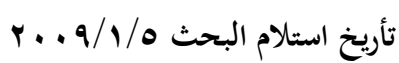


Sultan Ahmad Khleaf (PhD)

Assistant Professor

Technical Institution - Mosul

\begin{abstract}
The social natural of individual in the field of job has specified the building of relations, making groups, reaching to activate the coalition and social tolerance in order to decide sociability and certain of self power. The study tried to answer the question:

Have the workers in organization intellectual capacity towards the subject of coalition within their work field, within the context of factual reality and success factor without negative consideration. The study concluded a group of results:

1. Job coalition is a decisive matter and not avoidant.

2. Job coalitions are varied in power according to required situations and aiding factors in formation.

3. Job coalitions represent one of the effective strategies in the official work.

According to the above conclusions, the study suggest many recommendations
\end{abstract}

Key Words: Job Coalitions Application Study. JCAS

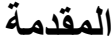

تمثل عملية الانضمام إلى الجماعات الوظيفية مدخلاً لصياغة وبناء علاقات اجتماعيـة

متباينة في أبعادها متنو عة في اتجاهاتها، وبما يفضي إلى احتماليـة قيام التحالفات فيمـا بينها

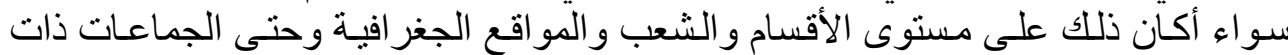

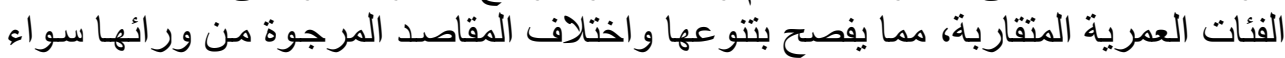
أكانت تتعلق بإثبات الهوية الشخصية أو النزعة إلى السيطرة والاستحو اذ على الموارد أودأ أو مـا

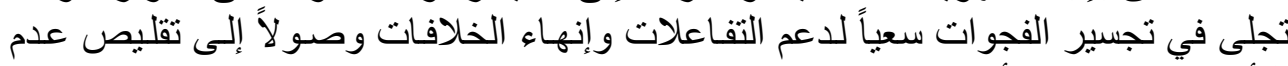

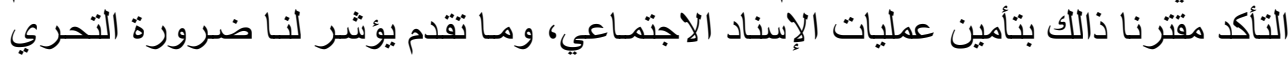

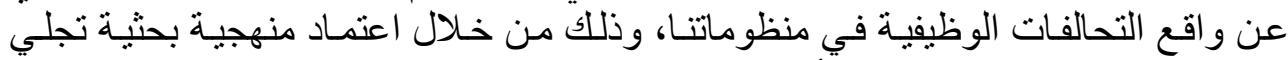

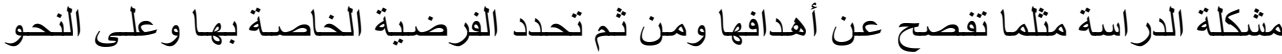
الآتي: منئن

\title{
أولاًا مشكلة الاراسة
}

نسج خيوط الارتباط ومد أواصر التفاعل بين أعضاء المناء المنظمـة قد يكون مدخلا لبنـاء

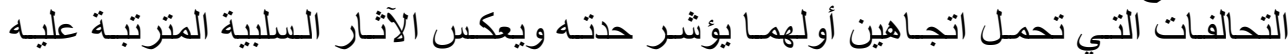

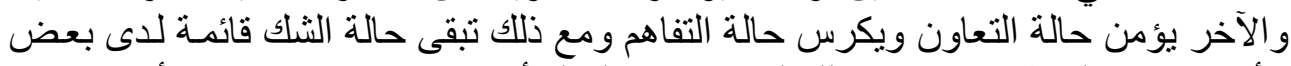

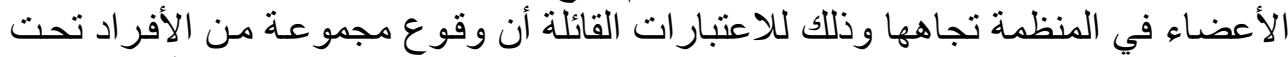

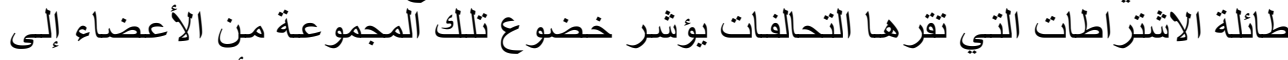

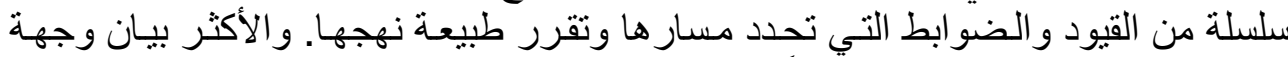

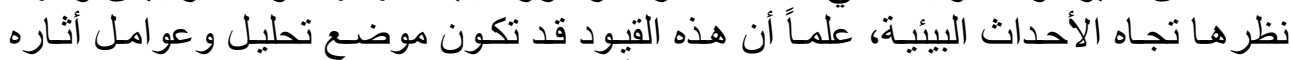

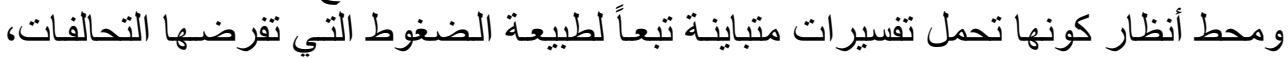




\section{خليف[1rv]}

ممـا يعكس الأثر الذي تمليه التحالفـات في الميدان الوظيفي للعـاملين، عليه تجلت مشكلة

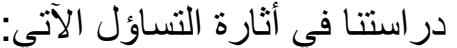

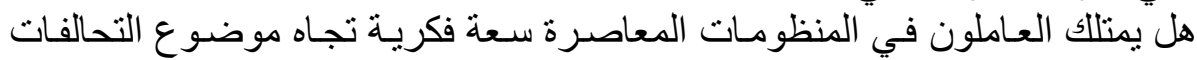

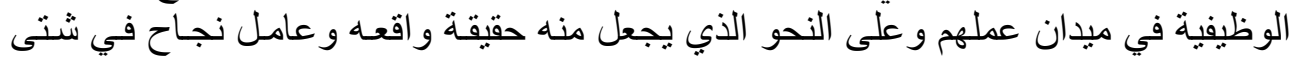

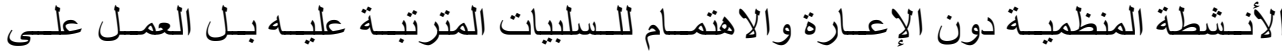

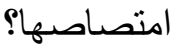

ثانياً - أهداف الاراسة

تكمن أهداف الدراسة في السعي لتحقيق الآتي:

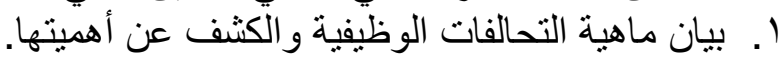

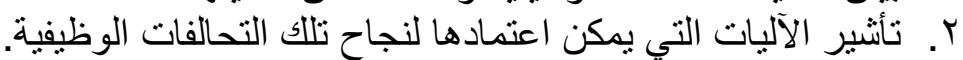

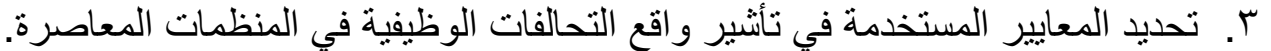

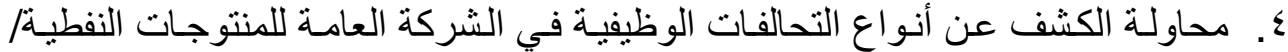

الثمالية

ثالثاً. فرضية الدراسة

يتحدد وجود التحالفات الوظيفية بتحقق المؤشرات المعبرة عنها (اتفاق النسبة الغالبة

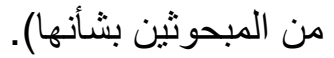

رابعاً- مجتمع الدراسة وعينته

تمثل مجتمع الدراسة بالثركة العامة للمنتوجات النفطية/الثمالية، وقد تم اختيـار عينـة

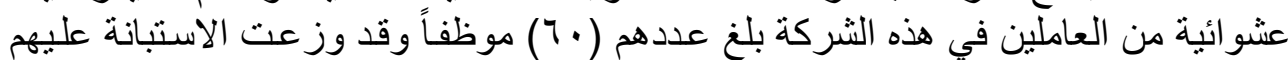

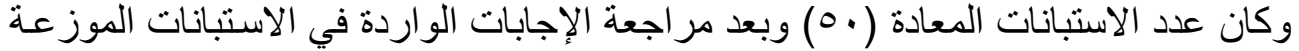

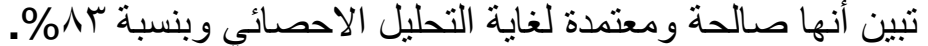

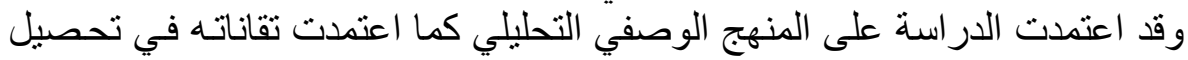
البيانات من الاستبانة وتم استخدام (النسب المئوية ومقياس شدة الاجابـة) في اختبار فرضية فئس

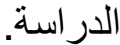

وسعياً لتحقيق أهداف الدراسة الحالية واختبار فرضيتها فقد تم تبني الأطر الآتية:

أولاًا الاطار النظري

\section{ا ـ ماهية التحالفات الوظيفية وأهميتها}

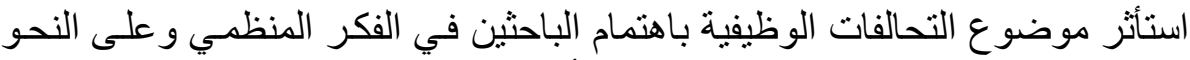

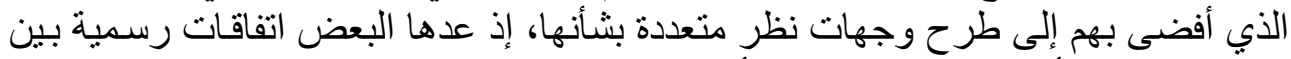

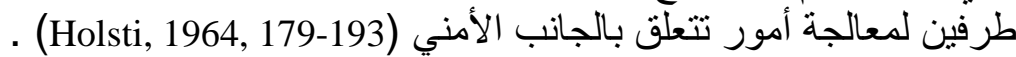
قي حين ذهب آخرون إلى القول بأنها المرحلة النهائية في خط التعاون التهاون بين المنظمـات

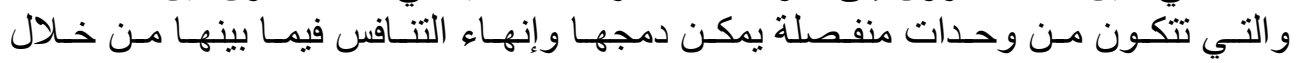
التحالفات (Atchison and Hill., 1978,312). 


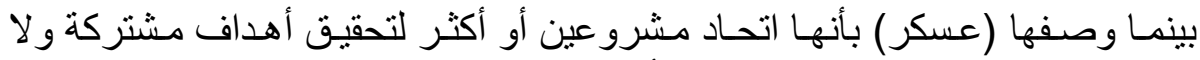

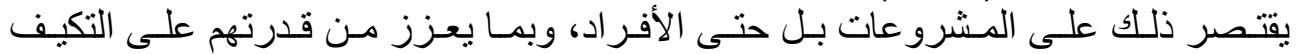

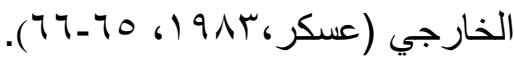

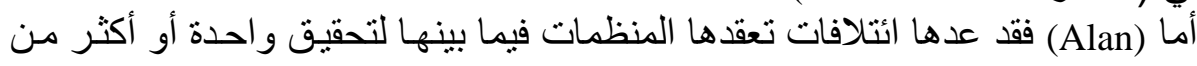
استر اتيجياتها (Alan 1994,329).

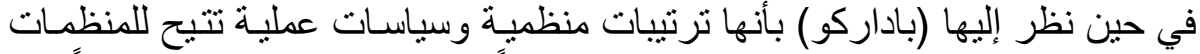

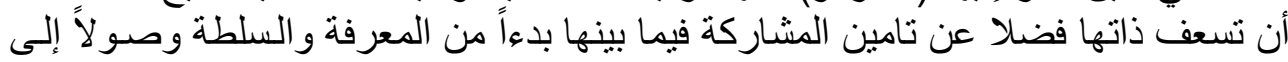

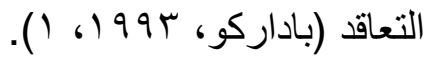
وبالمقابل هناك من عدها جماعات منظمية تمتلك قوة التأثنير في المخرجات القراريـة

.(Robbins, 1994, 244) وفـي الـسياق ذاتـهـ أشــار إلـى أنهـا جماعـات تتـشكل لتحقيـق أهـداف سياسـية. .(Wright. And Noe, 1996, 657)

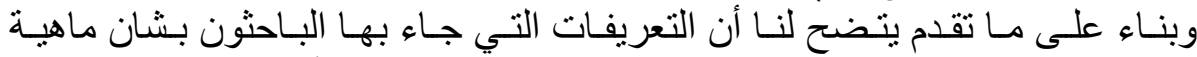

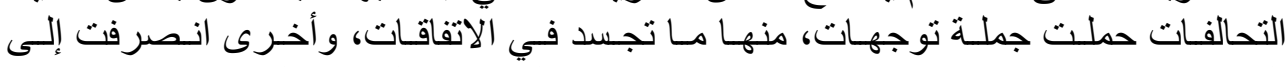

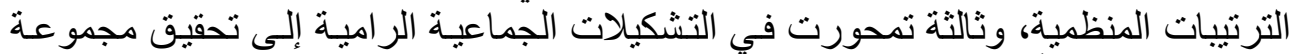

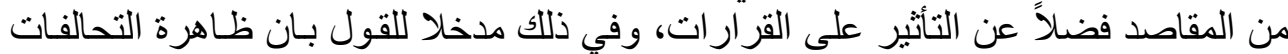

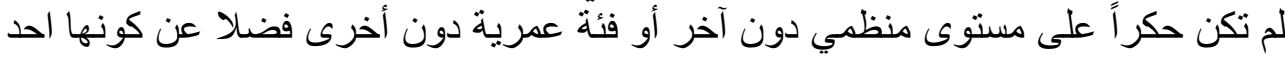

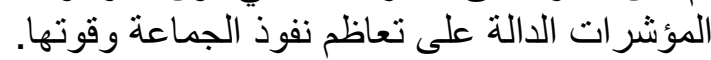

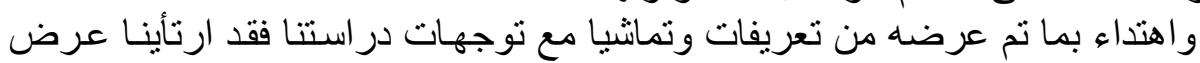

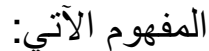

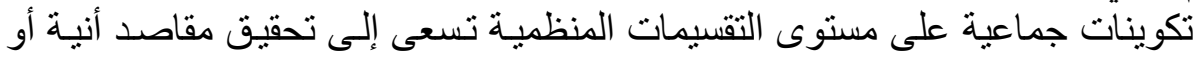

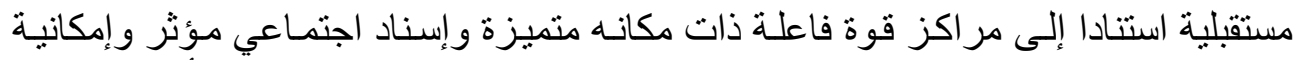

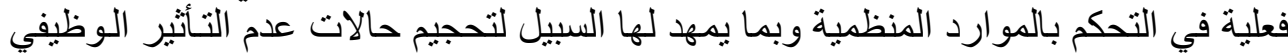

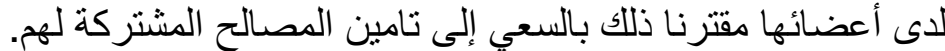

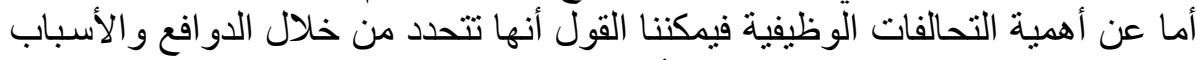

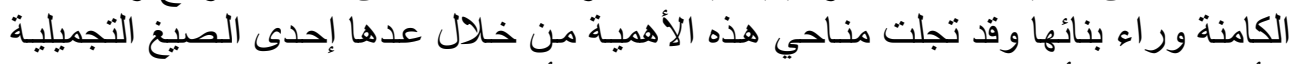

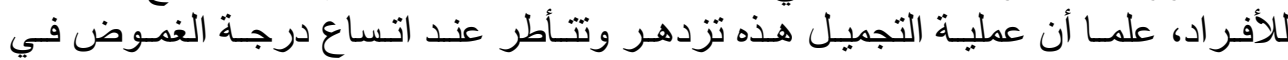

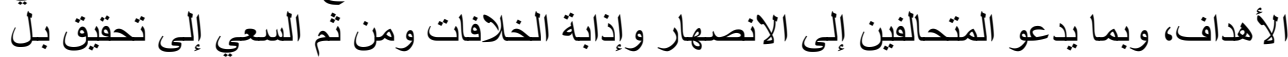
تحسين المصالح المستمرة لهم (Robbins, 1994, 248).

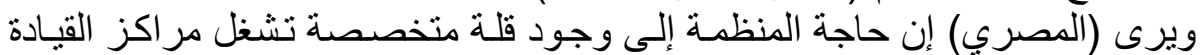

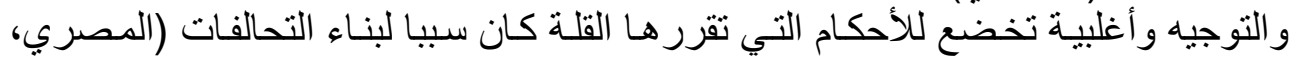

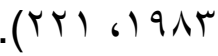
أما (Yiska) فقد أشارت إلى أن التحالفات مردها تقويم القدر ات و السعي إلى إضـعاف دور الجهات المناهضة من خلال كونها مصدر ضغط المات يهددهم (Liska,1962, 26-27).

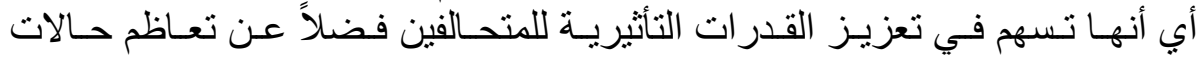

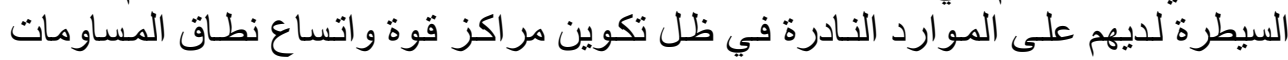
.(Burton. And Thakur, 1995, 149) وبما يفضي إلى المساهمة في تأمين حالـة التكيف للتغيير ات التي تقع ضمن نطساق

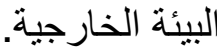




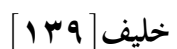

أي أن التحالفات تمثل طرفا فاعلا في التوازن الإستر اتيجي (Jerome.,1992, 38).

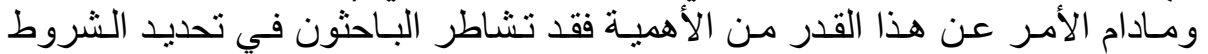

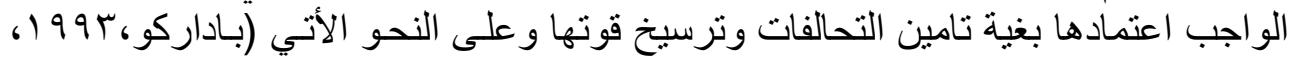
ـ الفهم الو اضح لقدر ات المنظمات حالياً ومستقبلياً. ـ تشخيص قيم وتطلعات الحليف الأخر. - تأثير طبيعة التحالفات المتوقعة التهنة مستقبلا. ـ تجنب التبعية المفرطة عند إقامة التحالفات. توافر الثقة بين المتحالفين.

وفي السياق ذاته أنشار (Wright and Noe., 1996, 657-661) إلى الوسـائل المعززة

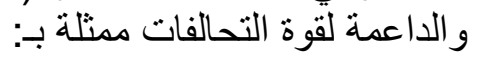
ـ اعتماد فكرة الثبكات الر امية إلى المشـاركة في المعلومـات بين المتحـالفين وبمـا يقود إلى صقل وتهذيب حالات الاحتكاك بينهم. - توظيف التحالفات لخدمة مصالح المتحالفين وبمـا يدعم النتائج المرجوة لهم ويديم حالات

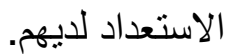

- ترسيخ فكرة الدفاع عن الأفكار والوصايا المنبثقة عن التحالفات و عدها مصدر قوة لديهم.

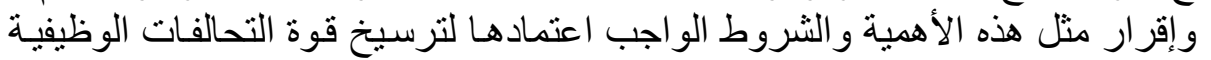

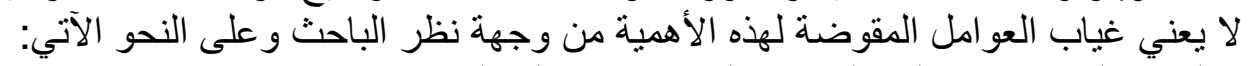

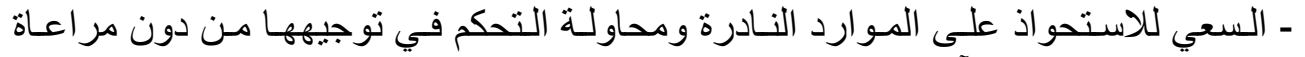
ل للاحتياجات الفعلية للآخرين.

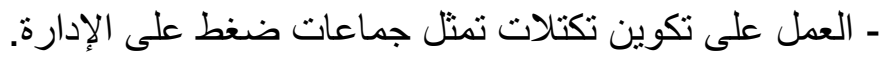

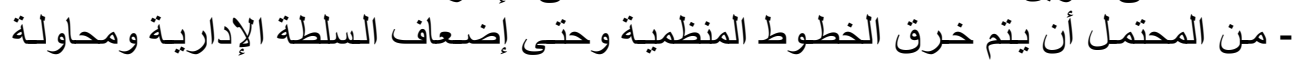
الالتفاف على بعض الإن الإجر اءتات.

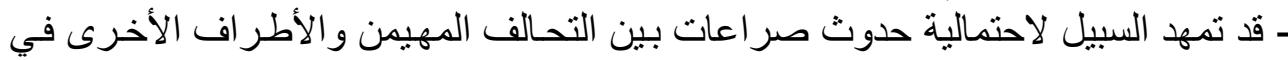

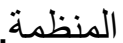

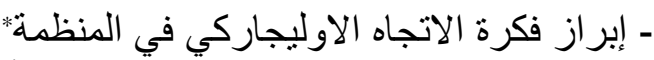

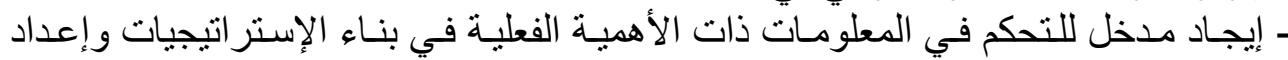

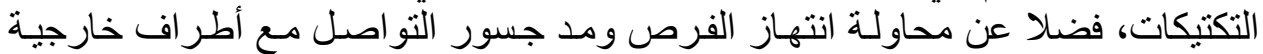
وحتى داخلية بغية تحقيق مكاسب أنبة أوناز أو مستقبلية.

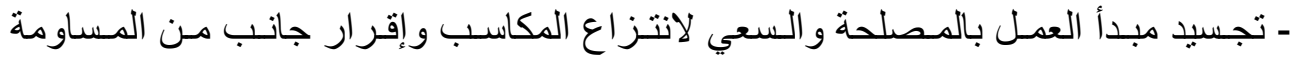

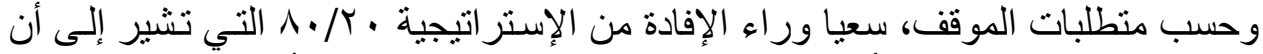

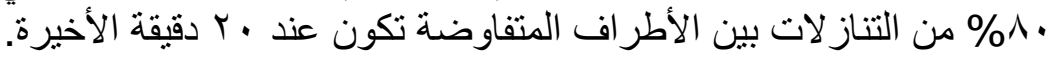

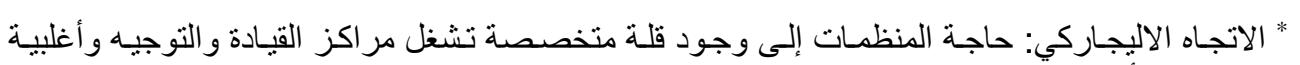

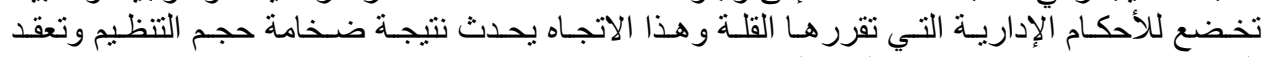


r. المعايير المؤشرة لقوة التحالفات الوظيفية

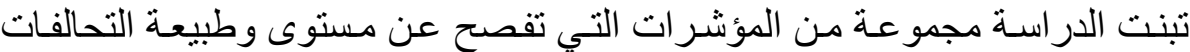
ومن ثم إقرار وجودها من عدمه، وقد تمثلت هذه المؤشرات بات بالاتي:

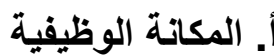

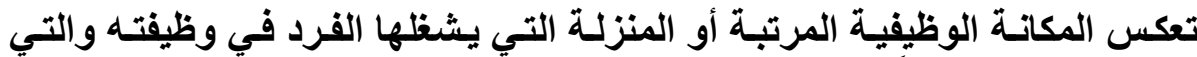

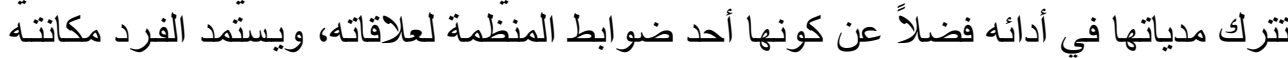

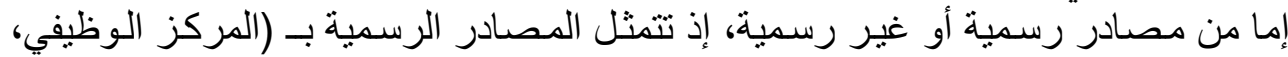

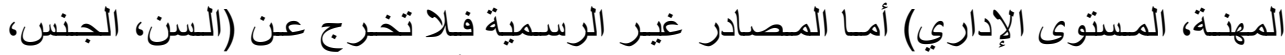

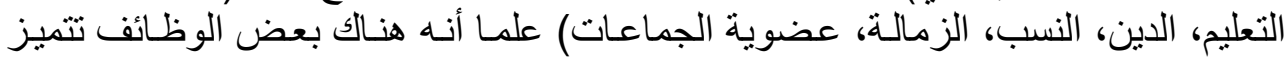

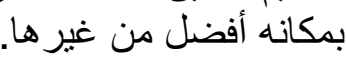

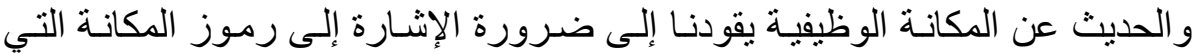

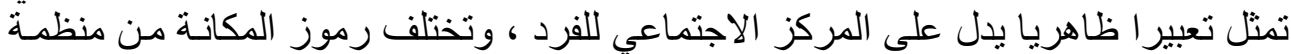

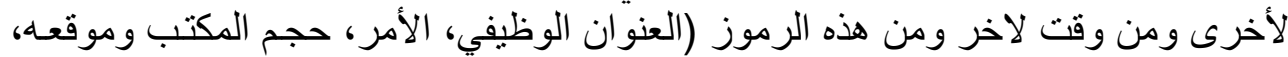

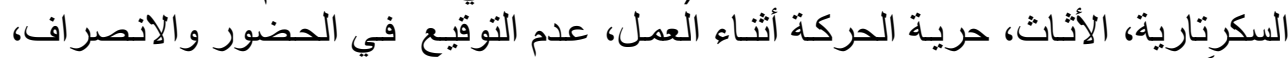

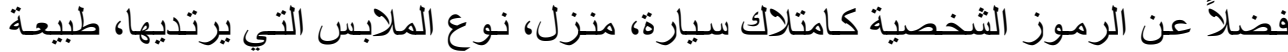

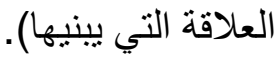
و لابد من التذكير بأن الفرد من ذوي المكانه العالية يعدد إلى استباق المبادرة لنفساه،

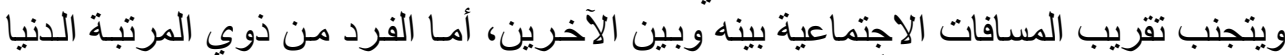

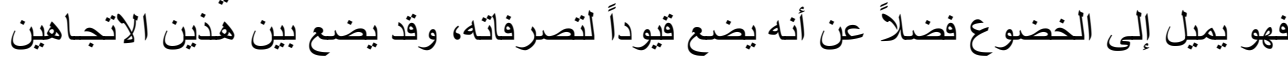
من ألمكانة (العالية و الدنبا) حالة تعكس درجة من الوسطية التي تجسد شعور الفرد بقدر من التئن

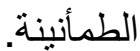
ولا يفوتنا القول بان ألمكانه الوظيفية قد ينتج عنها بعض الايجابيات كالقيم الايجابيـة

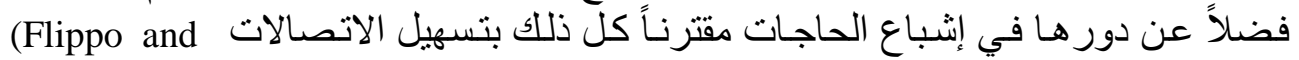

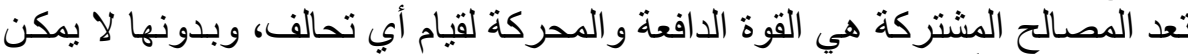

$$
\text { ب. المصالح المشتركة }
$$

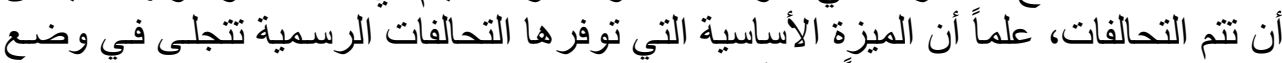

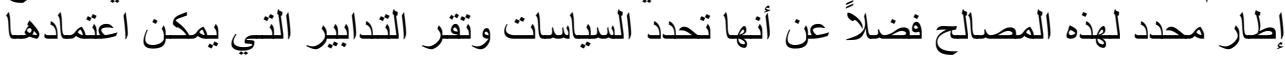

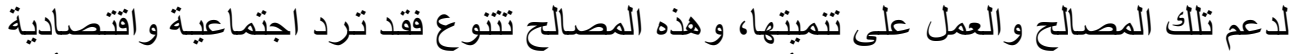

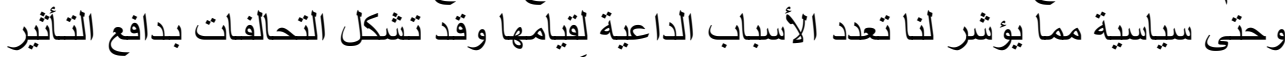

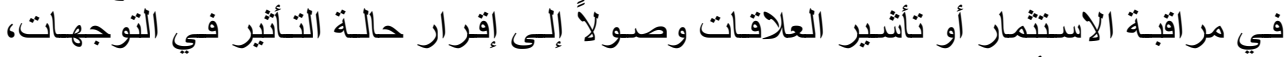

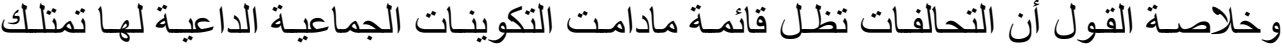

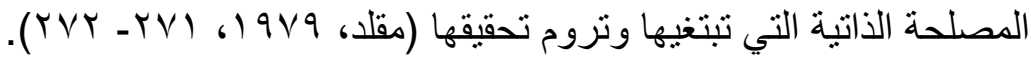

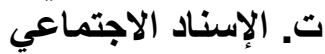
يتمثل بالاتجاه الّودي التعاوني الذي يمكن بناءه بين أعضاء الجماعة التي ينتمي إليها

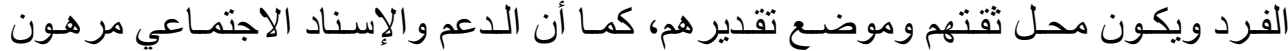

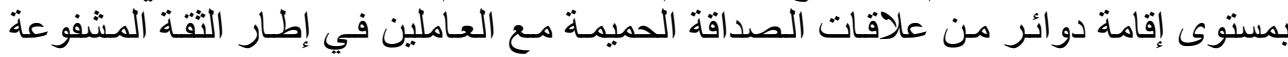




\section{خليف[1 [1 [1}

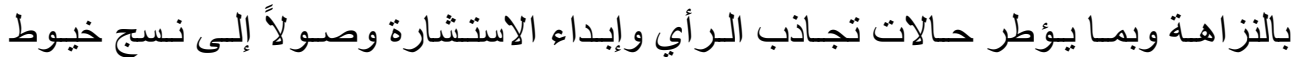

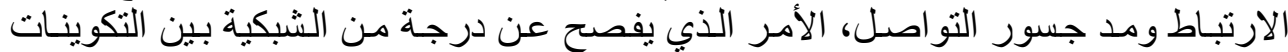

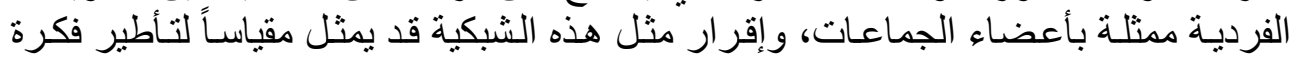
التحالفات و العمل بها محتو ا ومضمونا (Luthans, 1985, 89).

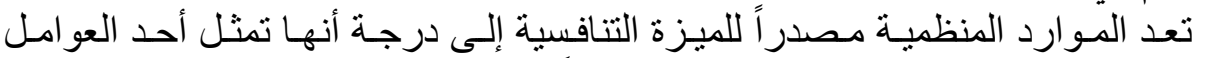

ث. التحكم في الموارد

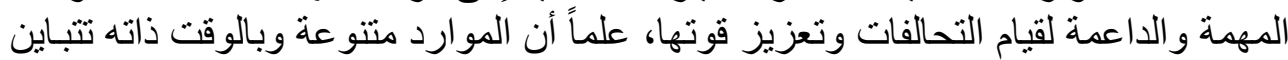

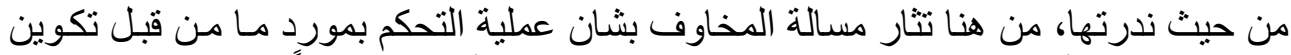

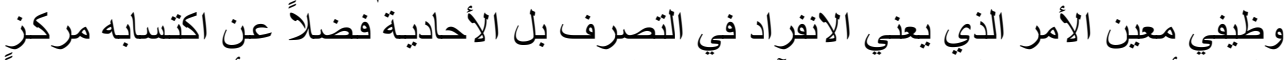

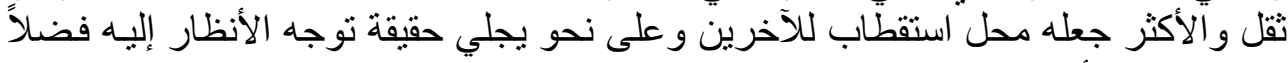
عن احتمالية تأثثر اته في رسم مسار القرار ات الإداريـة وفي هذا الصدد يشير (Robbins)

you can have power over them, If you have something that other's want

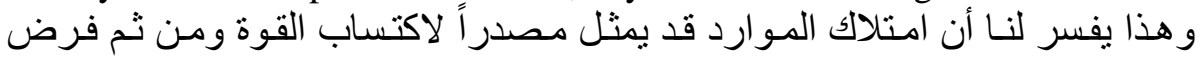

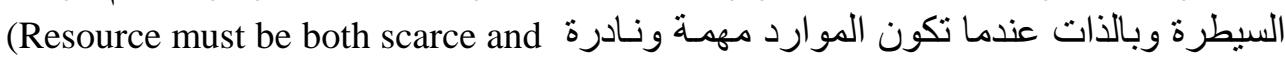

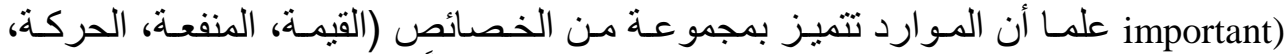

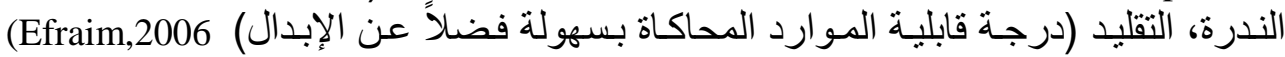

\section{ج. تحجيم عدم التأكد الوظيفي}

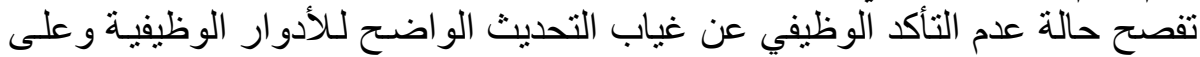

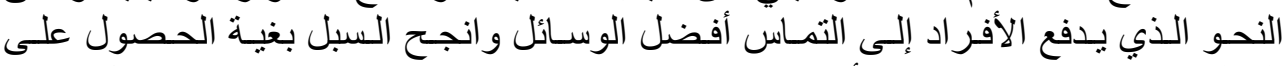

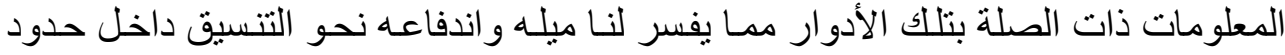

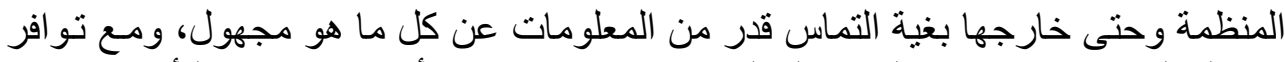

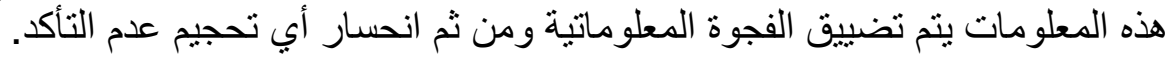

\section{r. أنواع التحالفات الوظيفية}

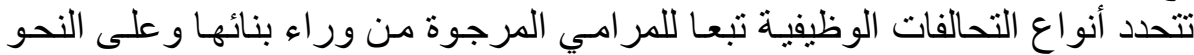

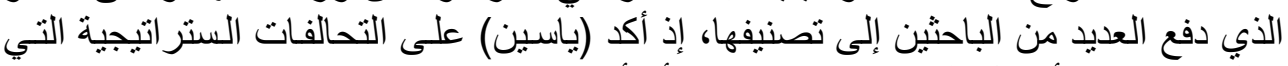

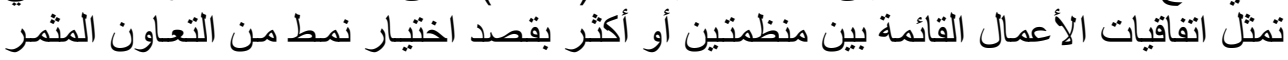

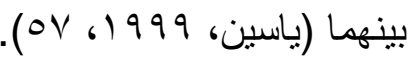

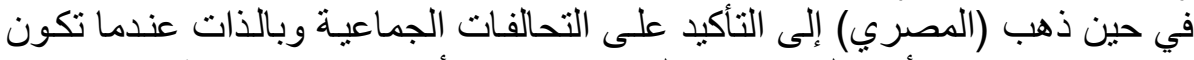

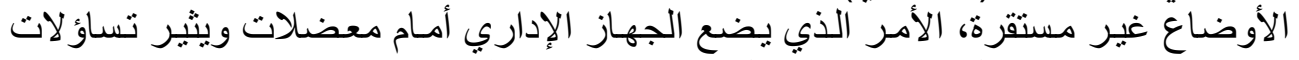

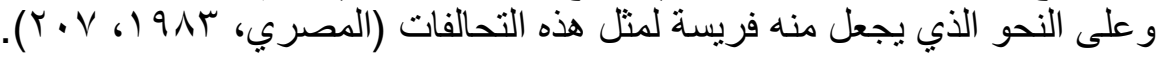

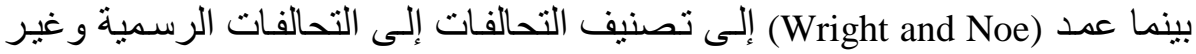
الرسمية (Wright and Noe1996,657-661). 


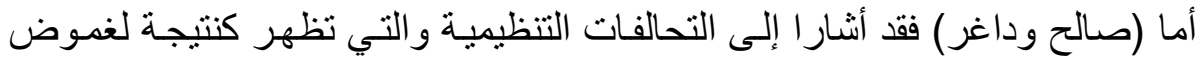

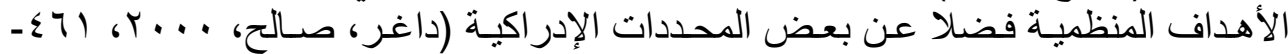

وبنـاء على مـا تقدم فقد خرج الباحث بتصنيف يتماثـى وتوجهات الدراسـة الحالية

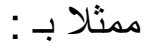
- التحالفات الخاصة بالمر اكز الوظيفية المتماتلة.

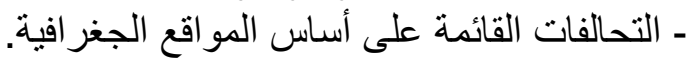
- 2 - تحالفات ذات المصالح المشتركة. ـ ـ التحالفات على أساس الاتنماءات (العشائرية مثلا).

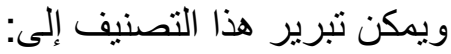

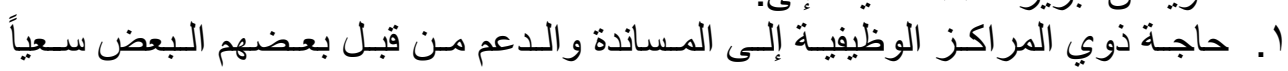

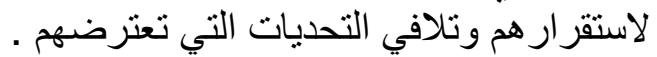
r. المصالح المشتركة تمثل محطة التقاء في مختلف المستويات الوظيفية وبمـا يملي عليهم

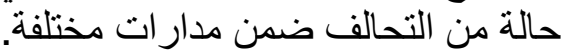

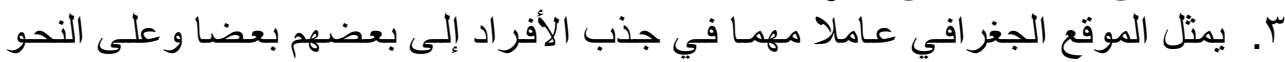
الذي يؤمن مستوى مرضيا من الدفاعات لديهم قد يكون من بينها التحالفات.

؛ ـ مداخل بناء التحالفات الوظيفية

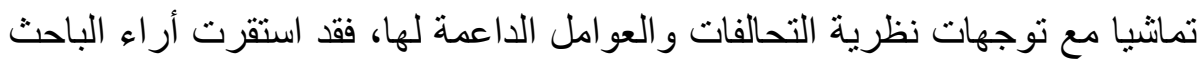
على وجود مجموعة من الدداخل تمثل المنطلق الأساس لها ممثلة بالاتي:

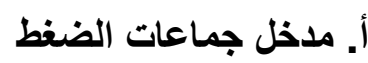

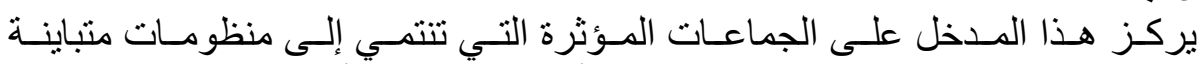

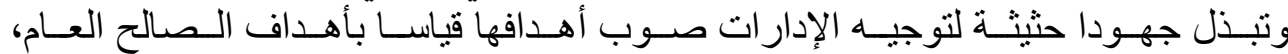

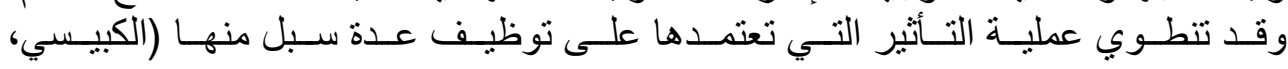
: (9)، r.... ـ النزوع إلى توجيه الدعوات و إقامة الو لائم.

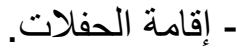

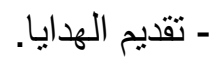

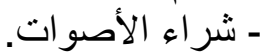

- ت توظيف المحسوبية والمنسوبية.

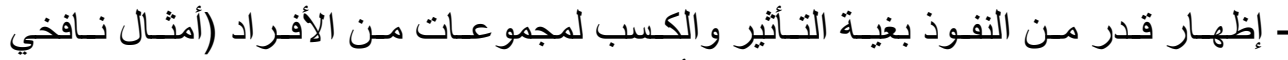

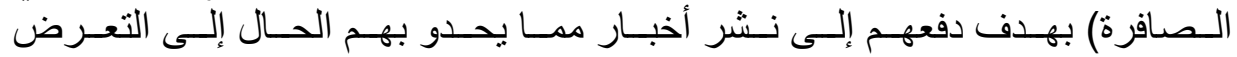

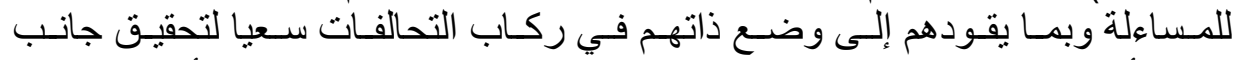

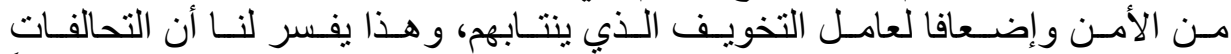

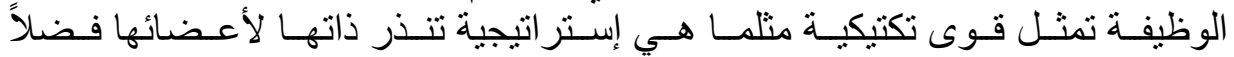

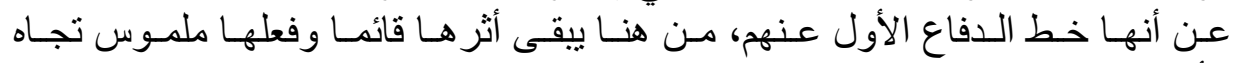




\section{خليف[بـ}

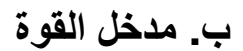

ينطلق هذا المدخل من القول بان احتضان الفرد في المجال الوظيفي من قبل تكوينـات

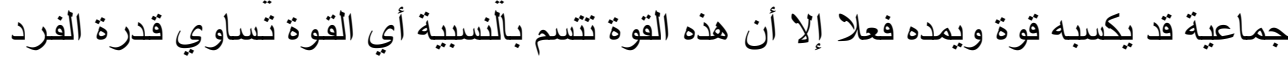

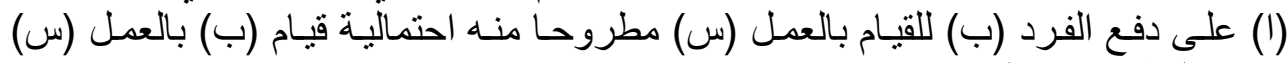

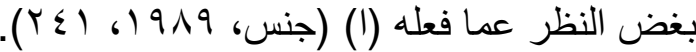
وفي ذلك مؤشر للقول بان القوة تعكس مستوى القدرة على التحكم في سلوك الآخرين

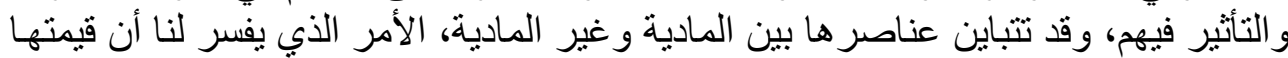

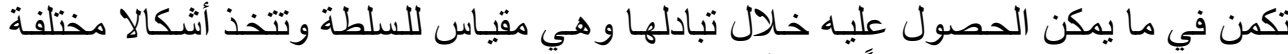

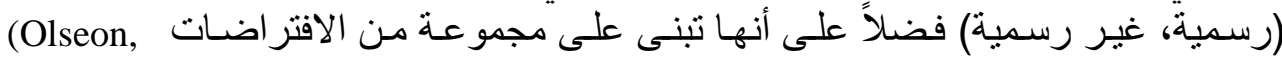

ا ا ـ القوة تحدث ضمن العلاقات الاجتماعية و التكوينات المنظمية.

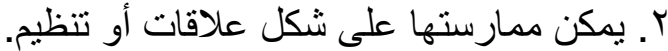
ب. تستمد من خلال التنظيمات الاجتماعية.

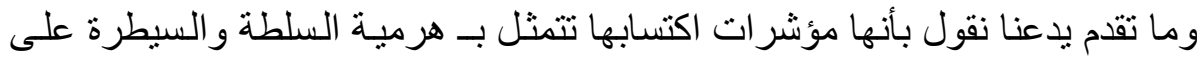

الموارد ومركزية الشبكية (Robins, 1994, 253).

وهذه بحد ذاتها تمثنل مصادر قوة، إلا طريقة استخدامها تعكس مستوى ممارستها فهذه تكون عامل إكر اه للآخرين مما يعيق فعلها ويثلم هيبتها أو تكون عامل إنها إغر اء مما يعني

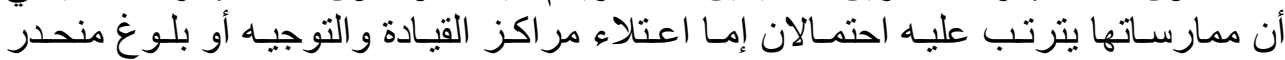

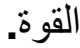

ت. ت مدخل الاستقطاب

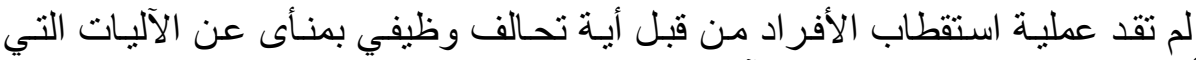

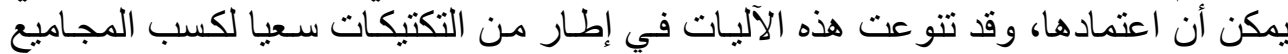

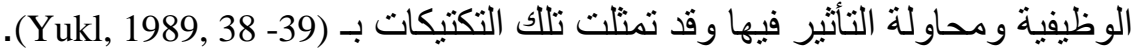

1 الإقناع العقلاني

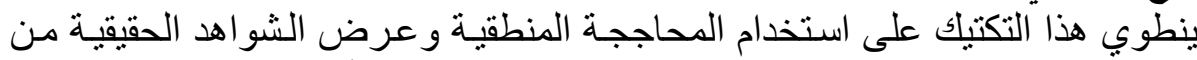

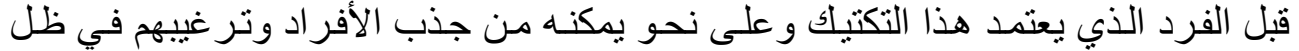

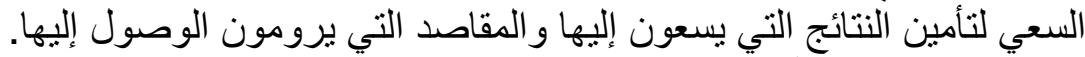

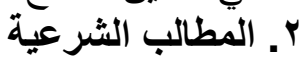
تتضح تلك المطالب من خـلال الأدوار و الممارسـات التي تؤديها السلطة في إطـار تحكمه السياسات و القو اعد المنظمية.

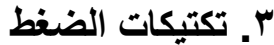

تتمحور في طلبـات الرؤسـاء وحالات التهديد الداخلي و الخـارجي وقد تقود هذه في بعض الحالات إلى نتائج غير مرغوبة التهات.

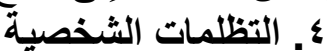

استخدام الصداقات الشخصية كأساس لتلبية وتقديم المساعدة ومن ثم الانضمام التصام إلى

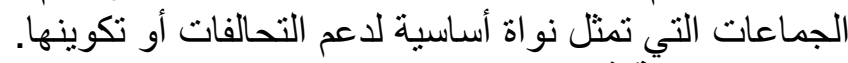
•ـ الدبلوماسية في التصرف توان 


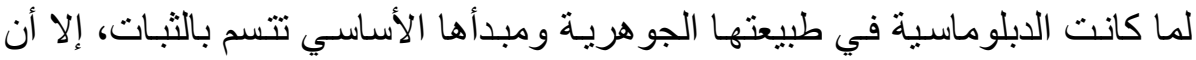

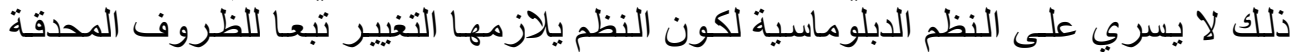

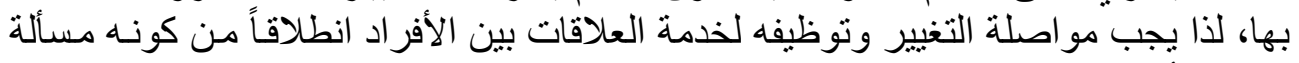

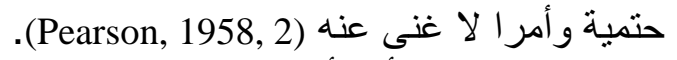

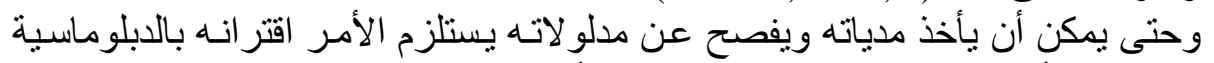

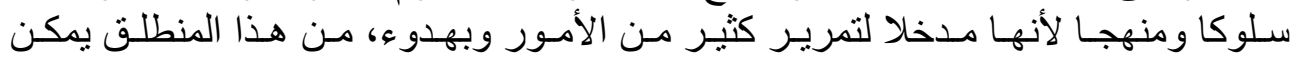
التحصن بها لجذب كثير من الأفراد و عدها مدخلا للتكيف مع كثير من المستجدات

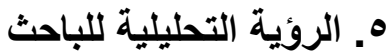

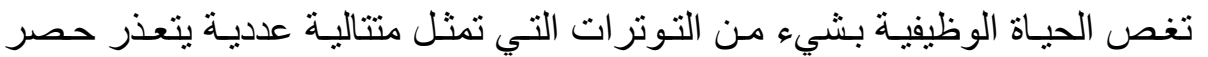

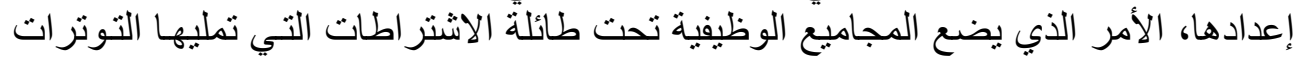

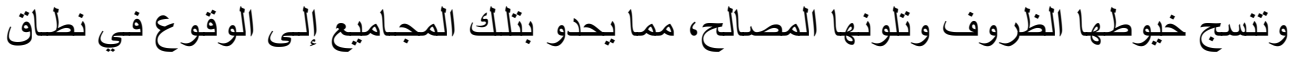

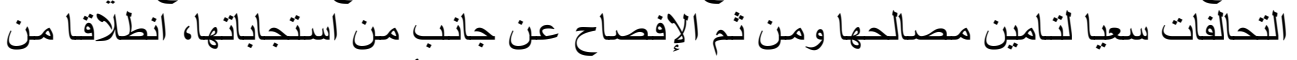

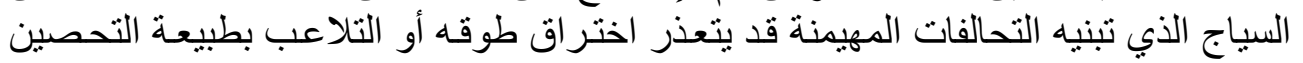

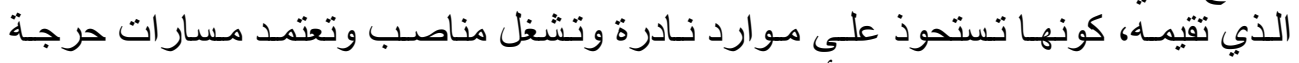

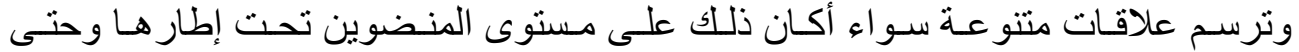

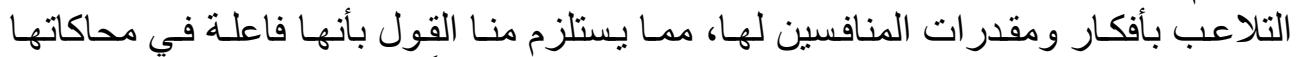

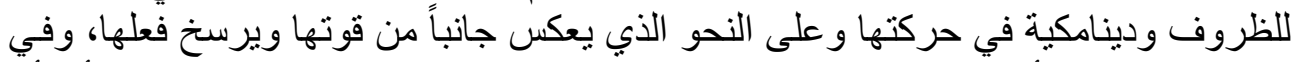

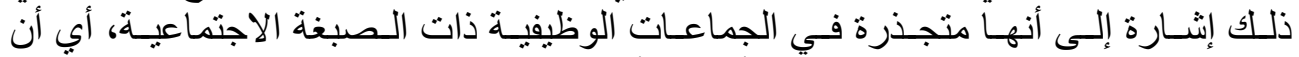

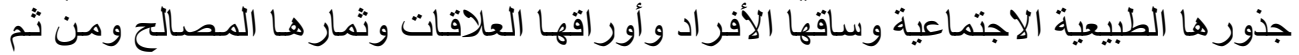

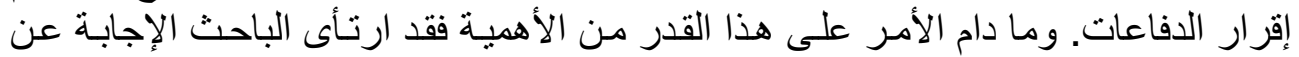

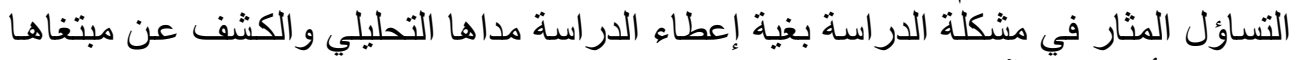

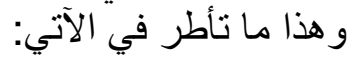

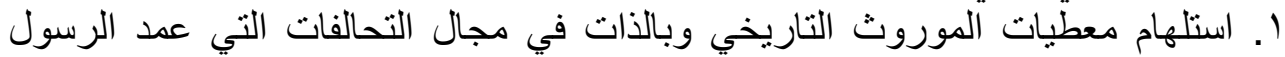

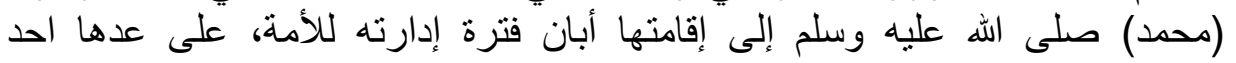

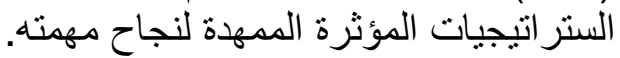

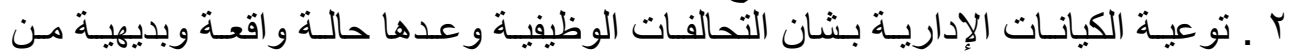
بديهيات العمل الوظيفي، بل التأكيد على الإفادة من مقدر اتها لتأمين الخدمة للصالح التحالح

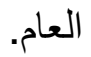
r. تعميق الروية تجاه التحالفات الوظيفية إلى حد عدها مسلكاً من بين مجموعة من المسالك

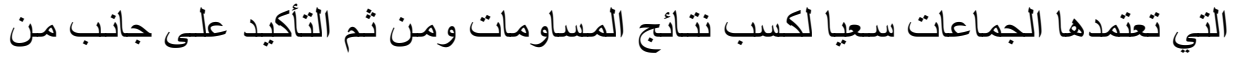

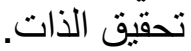

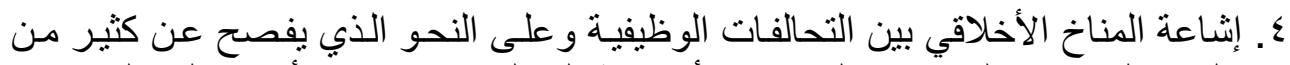

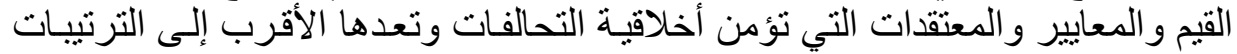

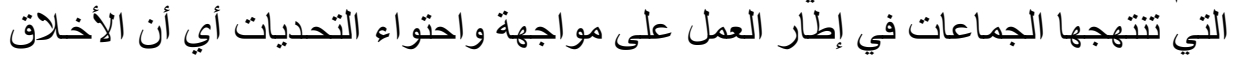

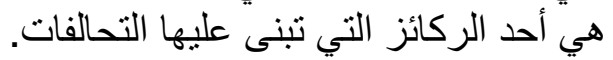

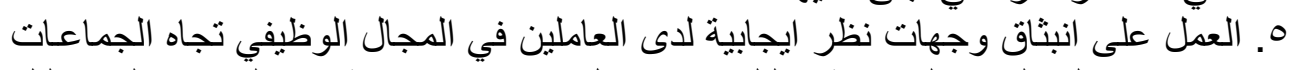

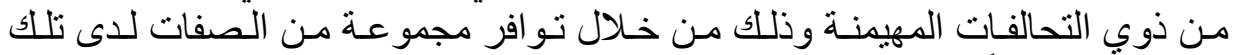

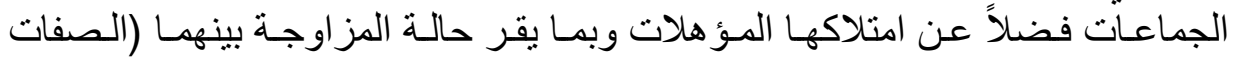




\section{خليف[0]}

بأخلاقياتها و المؤهلات بمدلو لاتها العلمية) و على النحو الذي يجسد الايجابية ويمنع شبح التوجس و السلبية.

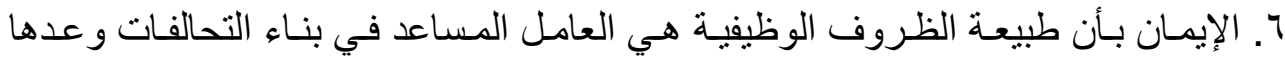

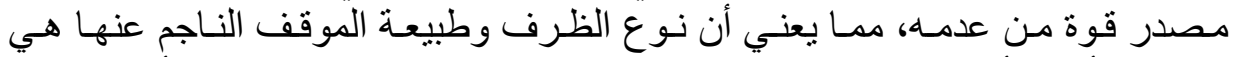

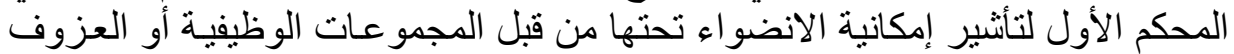

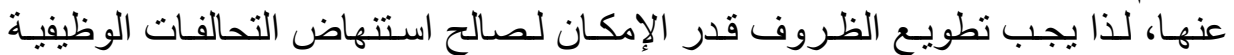

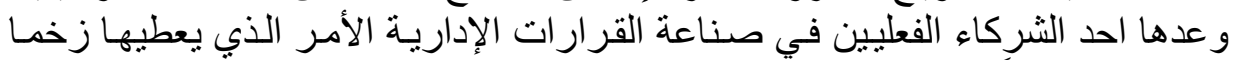

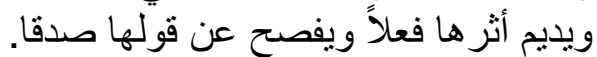

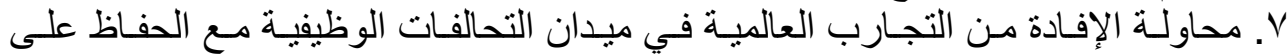

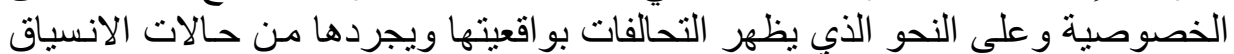

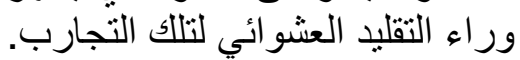

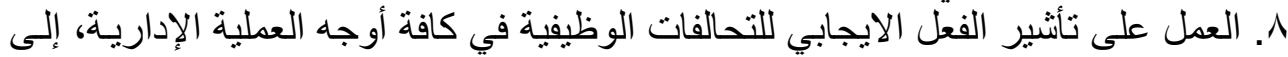

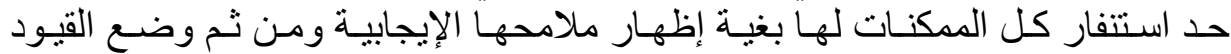
المحددة بل المعالجة لسلبياتها. 9. تنسيق الإدار ات التنظيمية مع قادة التحالفات المهيمنة بغية احتو اء العاملين المؤثرين من

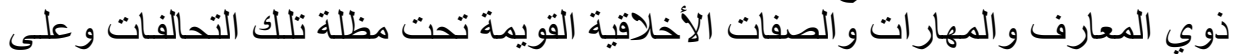
نحو بظهر السمة الصحية لها بعيدا عن أية انتقادات قد تتفذ بحقها.

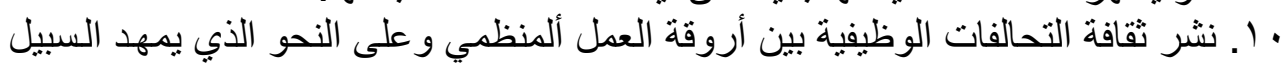

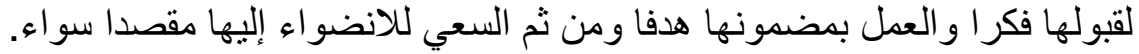

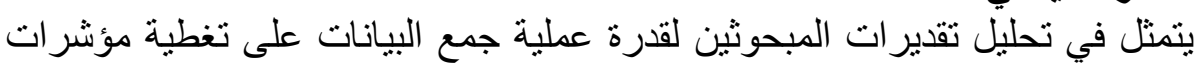

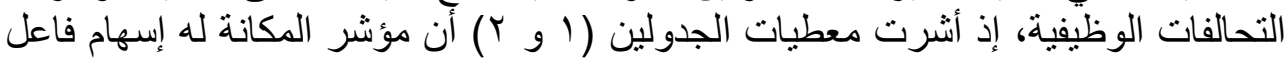

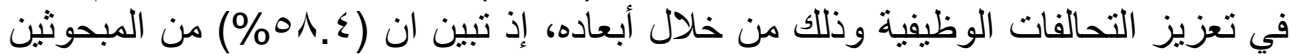

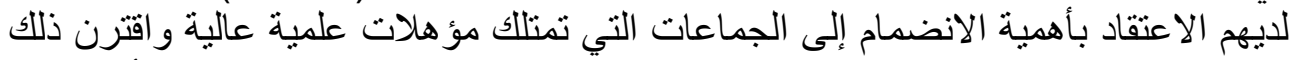

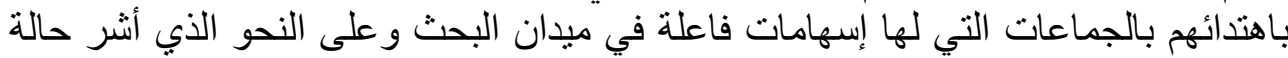

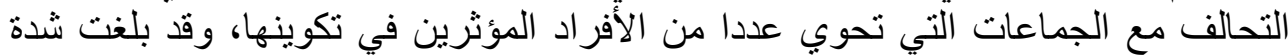

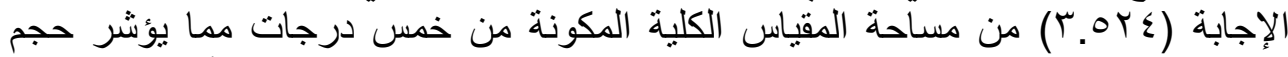

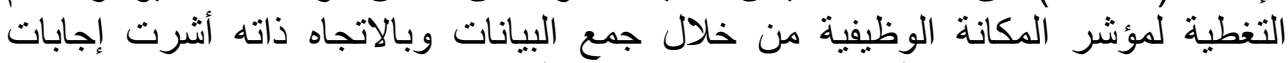

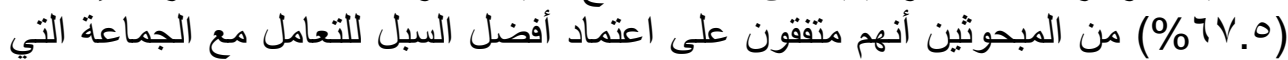

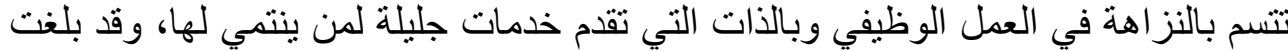

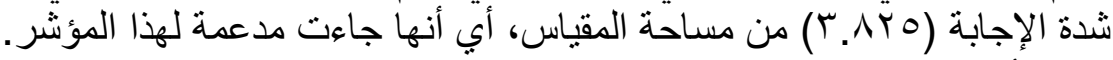

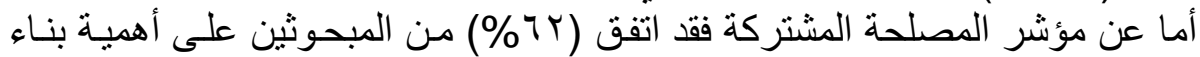

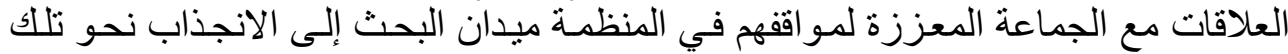

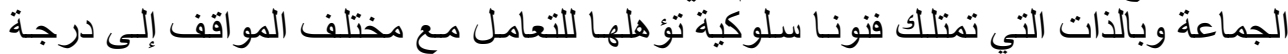
الدفاع عن أعضائها.

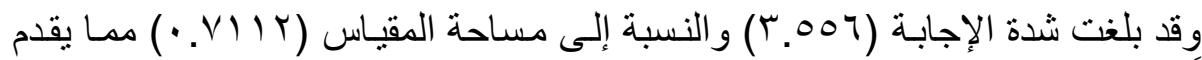
تصور اً حول تغطية عملية جمع البيانات لهذا المؤشر ، ويبقى لمؤشر السيطرة على المئ الموارد

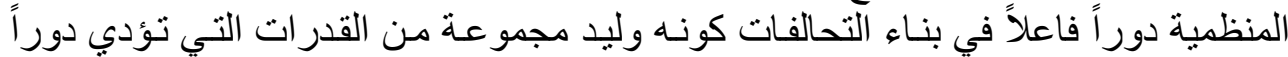




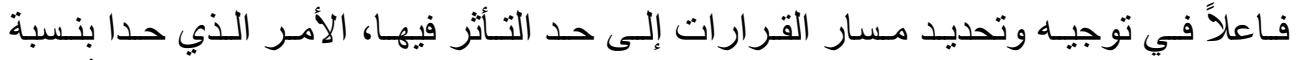

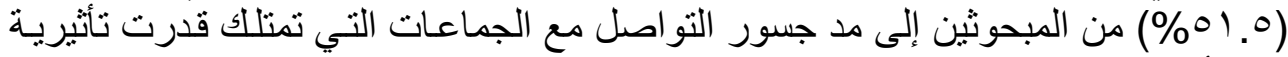

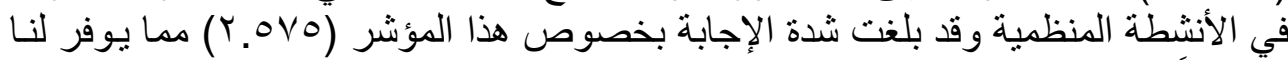

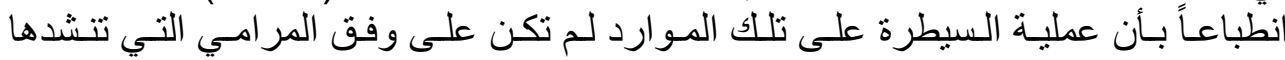

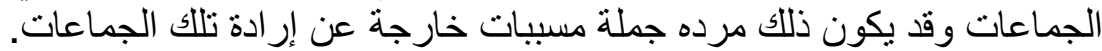

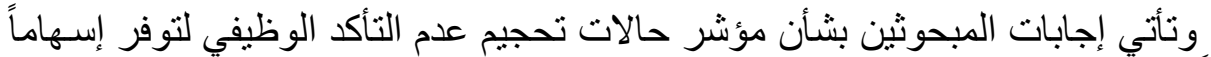

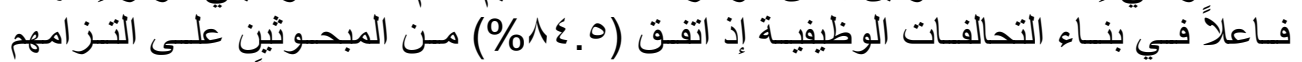

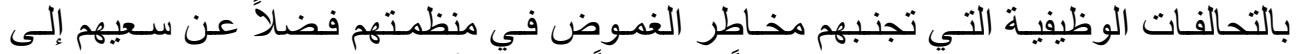

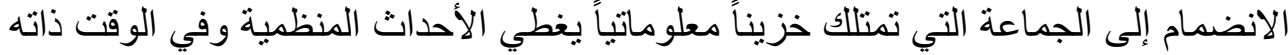

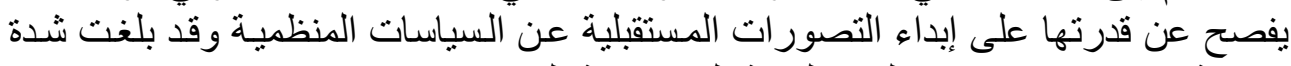

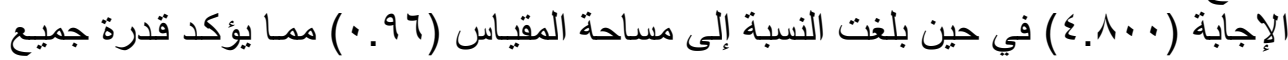
البيانات على تغطية هذا المؤشر.

\begin{tabular}{|c|c|c|c|c|c|c|c|c|c|c|}
\hline \multicolumn{11}{|c|}{ 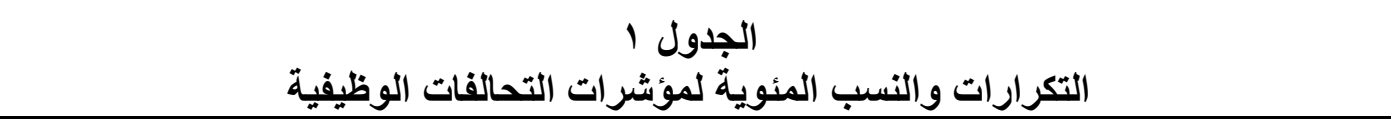 } \\
\hline ي بثدة & لا تأ & فقق & & تأكد & & ق & & بشثدة & اتفق & المؤشرات \\
\hline$\%$ & $ت$ & $\%$ & $ت$ & $\%$ & $ت$ & $\%$ & $ت$ & $\%$ & $ت$ & المكانة \\
\hline$\because V Y$ & r.7. & GY.KY & 11.7. & $\because .94$ & $\varepsilon .7$. & $\cdot r \wedge . \wedge$ & 10.5. & $\cdot . r 9.7$ & $1 \leqslant . \wedge$. & الوظيفية \\
\hline . ro & 1.50 & .100 & V.Vo & $\because 1 \leqslant 0$ & V.YO & & 17 &.$r 00$ & IV.VO & الاجتماعي \\
\hline$\because \leqslant 0$ & T. TO & .180 & 1. Vo & .17 & $\wedge$ & . $\leqslant 1$ & $r \cdot .0$ & $\cdot . Y^{\prime}$ & $1 . .0$ & المشتركة \\
\hline. .0 & r.o & $\because Y \Lambda$ & $1 \varepsilon$ & .100 & $\vee . \vee O$ & $\cdot r 00$ & IV.Vo &. .17 & $\wedge$ & المبيطرة \\
\hline - & - & $\because$ Vo & r.vo & $\because \cdot 1$ & $\varepsilon$ & .0 .0\%० & YT.VO & • & 10.0 & 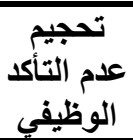 \\
\hline
\end{tabular}




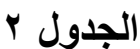

شدة الإجابات ونسبتها إلى مساحة المقياس لمؤشرات التحالفات الوظيفية

\begin{tabular}{|c|c|c|}
\hline النسبة إلى مساحة & شدة الإجابة & المؤشرات \\
\hline$\frac{3.524}{5}=0.7048$ & $\begin{array}{l}\frac{14.8 \times 5+15.40 \times 4+4.60 \times 3+11.60 \times 2+3.60 \times 1}{50} \\
=3.524\end{array}$ & الوظيفية \\
\hline$\frac{3.825}{5}=0.765$ & $\begin{array}{l}\frac{17.75 \times 5+16 \times 4+7.25 \times 3+7.75 \times 2+1.25 \times 1}{50} \\
=3.556\end{array}$ & الاجثماعي \\
\hline$\frac{3.556}{5}=0.7112$ & $\begin{array}{l}\frac{10.5 \times 5+20.5 \times 4+8 \times 3+8.75 \times 2+2.25 \times 1}{50} \\
=3.556\end{array}$ & المشتركة \\
\hline$\frac{2.575}{5}=0.515$ & $\begin{array}{l}\frac{8 \times 5+17.75 \times 4+7.75 \times 3+14 \times 2+2.5 \times 1}{50} \\
=2.575\end{array}$ & السيطرة \\
\hline$\frac{4.800}{5}=0.96$ & $\begin{array}{l}\frac{15.5 \times 5+26.75 \times 4+4 \times 3+3.75 \times 2}{50} \\
=4.800\end{array}$ & تحجيم عدم الوظيفي \\
\hline
\end{tabular}

\section{الاستنتاجات}

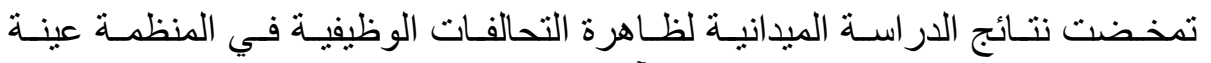

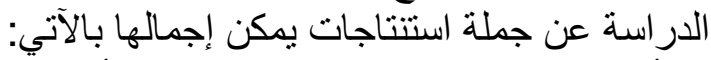

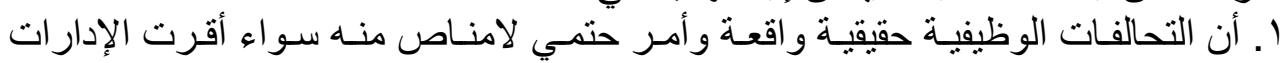

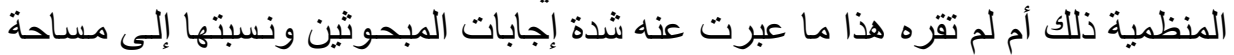

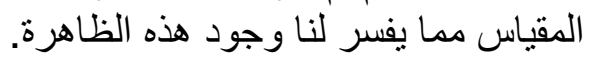

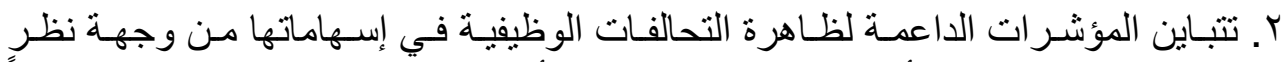

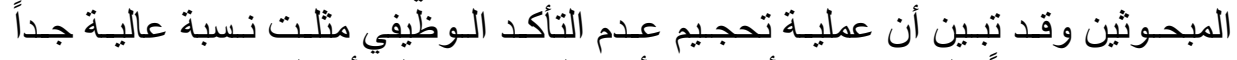

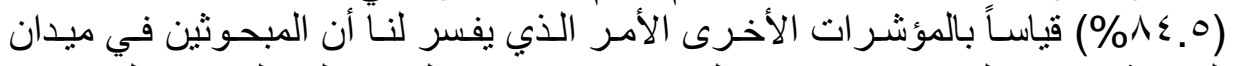

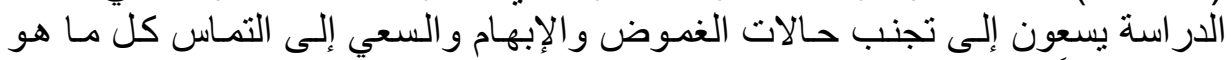

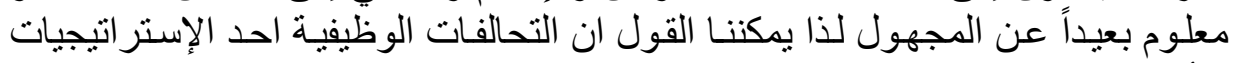

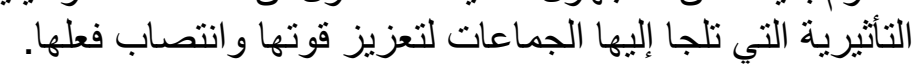

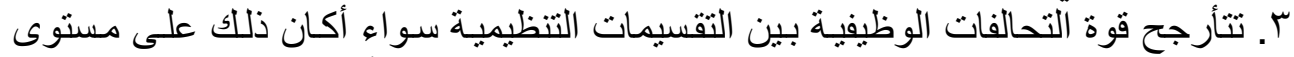

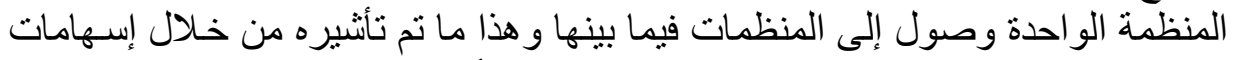

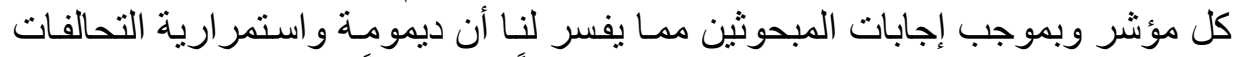

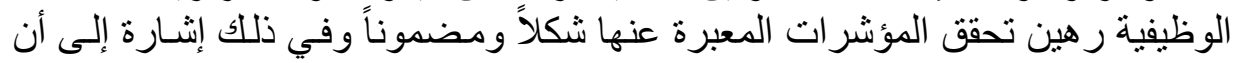


هذه التحالفـات تتعزز قوتها بمستوى تحقق الأهداف الثخصية لأفر ادها وتأمين كافـة

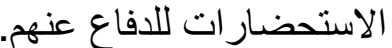

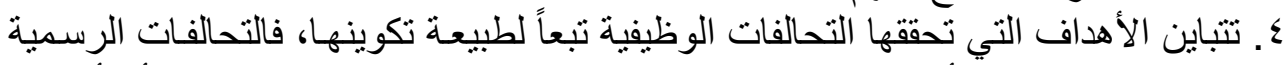

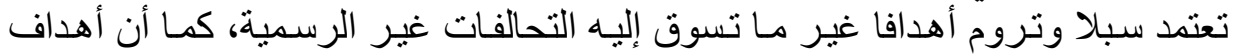

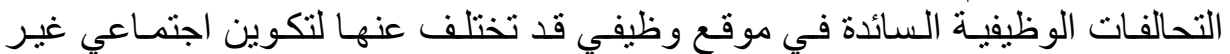
وظيفي. ه. التحالفات الوظيفية تلازمها التغييرات فهي بين مد وجز، اتساعاً وضيقاً إلى حد تشبيهها بالظو اهر المناخية.

بناءً على ما تم الكشف عنه من استنتاجات فقد خلصت الدراسـة إلى عدة توصيات التوصيات منها: ا ـ ضرورة احتو اء الإدارات المنظمية للتحالفات الوظيفية وعدها مدخلاً يمكن الإفـادة منـه

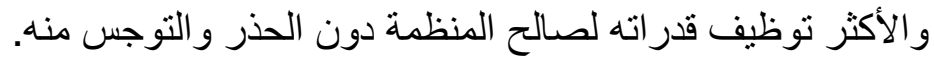

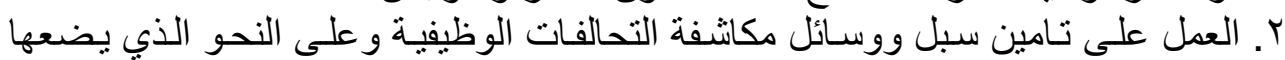

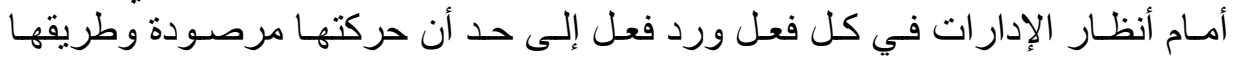

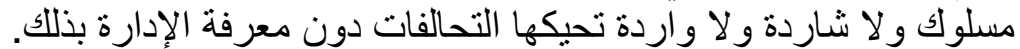

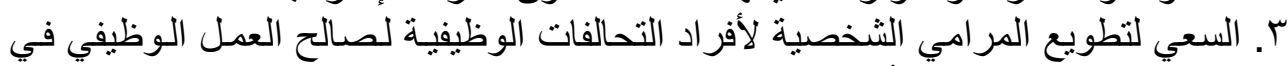
ظل ربط هذه المر امي بأهداف وتطلعات المئ المنظمة.

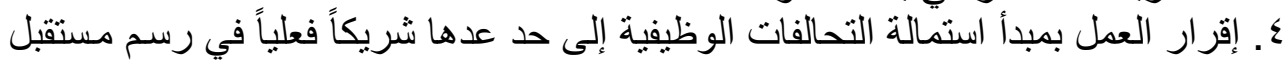

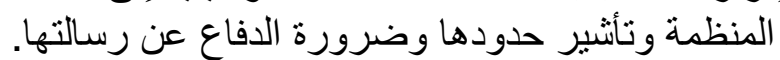

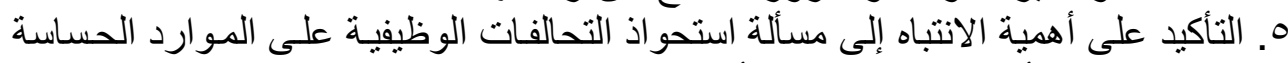

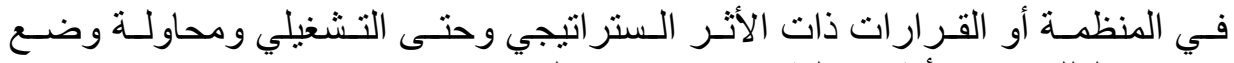

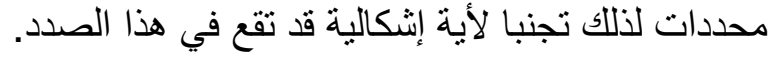

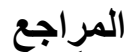

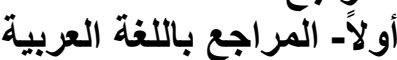

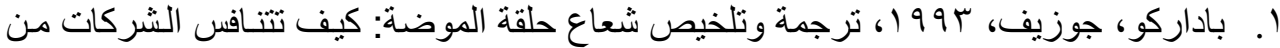
خلال التحالفات الإستر اتيجية، خلاصات الثركة الثرات العربيـة للعـام العربي العددي الثامن، السنة

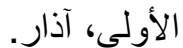

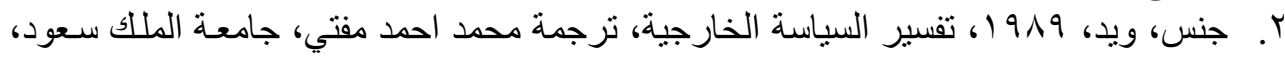

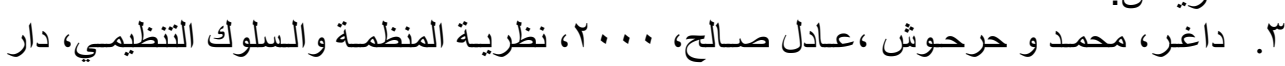

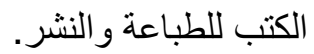

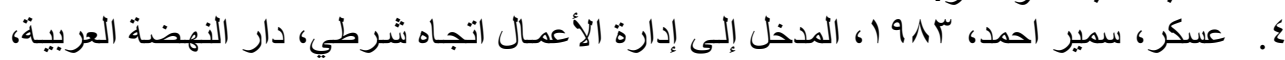

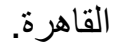

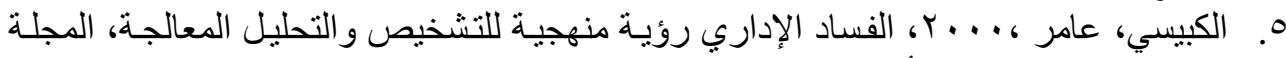

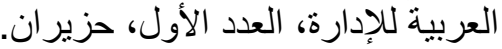

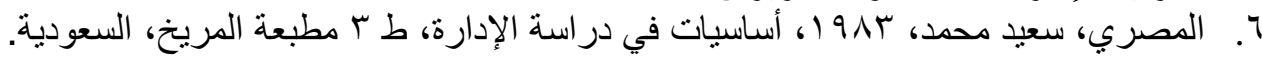




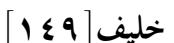
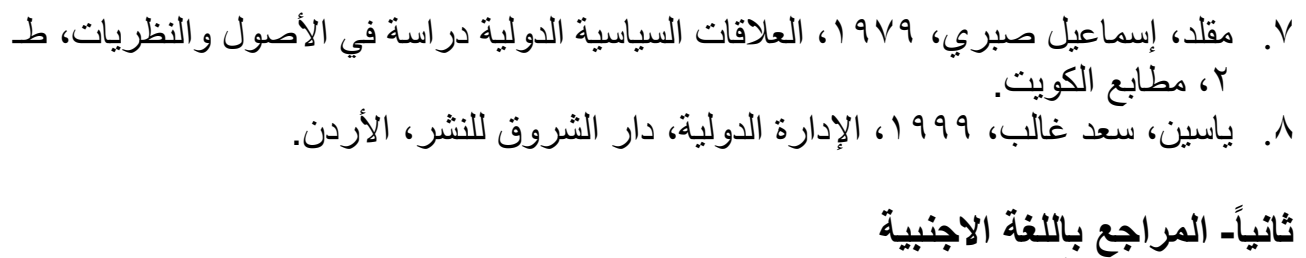

1. Alan, R., 1994, Strategic Management a methodological approach, $4^{\text {th }}$. ed., Addis ion - Wesly publishing Co, Inc., U.S.A.

2. Atchison,T.J. and Hill, W.W., 1978, Management to day, Harcourt brace Jovanovich ,Inc., U.S.A .

3. Burton, G. and Thakur, M., 1995, management day principle and practice, McGrawHill publishing company limited, new Delhi.

4. Efraim L., T., Ephraim, D. M., and Jems, W., 2006, Information Technology Transforming organization in the digital economy, $5^{\text {th }}$. ed. John Wiley and Sons, Inc., New York.

5. Flippo, E.P. and Munsinger, G., 1978, management Boston: Allyin and Bacon, Inc.

6. Holsti, K.J., 1964, the concept of power in the study of international Relations, Background .

7. Jerome, K., 1992, managing with information, $4^{\text {th }}$.ed., prentice - Hall, Inc., New Jersy.

8. Liska,G.1957, International Equilibrium: A theoretical Easy on Political and organization of society, Harvard university peers.

9. Luthans, F., 1985, organization Behavior, McGraw - Hill Book, New York.

10. Olsen, M. E.,1968, the process of social organization in the digital economy, $5^{\text {th }}$.ed., John Wiley and Sons, Inc., New York .

11. Pearson, L.,1985, Diplomacy in the nuclear age, Cambridge .

12. Robbins, S. P., 1994, organization theory, structure design and applications, $3^{\text {rd }}$. ed., prentice - Hall, International Inc.

13. Wright, P. M and Noe, R. A., 1996, Management of organization, McGraw - Hill, Inc., company, U.S.A.

14. Yukl, G. A., 1989, leadership in organizations, $2^{\text {nd }}$., prentice - Hall International, Inc., U.S.A . 